\title{
Intervenções no meio urbano para espaços socialmente sustentáveis ${ }^{1}$
}

\section{Interventions in the urban environment for socially sustainable spaces}

\author{
Esteves, Juliana Cardoso'; Castro, Carolina Maria Pozzi de 2; \\ 1 Universidade Federal de São Carlos, Rodovia Washington Luís (SP-310), KM \\ 235, São Carlos-SP, Brasil, juesteves@gmail.com \\ 2 Universidade Federal de São Carlos, carolmcastro@gmail.com
}

\begin{abstract}
RESUMO
O presente artigo visa fazer uma reflexão sobre novas formas de intervenção no espaço público, em que a própria comunidade se organiza e realiza mudanças tanto no meio físico urbano como no comportamento das pessoas e fazer uma breve discussão se a dimensão social da sustentabilidade pode ser verificada nessas ações. O trabalho é baseado em revisão bibliográfica sobre o tema, através da qual pudemos citar alguns exemplos e características comuns de movimentos que envolvem participação popular e outros organizados pela sociedade civil nas intervenções no espaço público, tema que contribui para a discussão do subtema sobre Governança e participação popular proposto para o evento.
\end{abstract}

Palavras-chave: espaços públicos, intervenção no meio urbano, qualidade de vida nas cidades.

\begin{abstract}
This article aims to reflect on new forms of intervention in the public space, in which the community itself organizes and makes changes in the urban physical environment and in the behavior of people and make a brief discussion about whether the social dimension of sustainability can be verified in these actions. The work is based on a bibliographical review on the subject, through which we could cite some examples and common characteristics of movements that involve popular participation and others organized by civil society in interventions in the public space, theme that contributes to the discussion of the sub-theme on Governance and participation proposed for the event.
\end{abstract}

Keywords: public spaces, interventions in the urban environment, quality of life in cities.

\section{INTRODUÇÃO}

A preocupação com as questões de sustentabilidade e qualidade de vida das pessoas é central na administração das áreas urbanas, colocando-se como um dos maiores desafios ao desenvolvimento urbano nesse século XXI. Criar cidades mais sustentáveis é uma das grandes

\footnotetext{
${ }^{1}$ ESTEVES, Juliana Cardoso; CASTRO, Carolina Maria Pozzi de. Intervenções no meio urbano para espaços socialmente sustentáveis. In: II SIMPÓSIO NACIONAL DE GESTÃO E ENGENHARIA URBANA: SINGEURB, 2019, São Paulo. Anais... Porto Alegre: ANTAC, 2019.
} 
missões dos administradores públicos e da sociedade civil, exigindo urgência na melhoria dos espaços públicos. Porém, o Estado não tem sido capaz de atender às demandas da população e se assiste a inúmeros conflitos envolvendo direitos sociais, assim como déficits no tocante às necessidades básicas.

Na cidade contemporânea, destaca-se a importância da revalorização dos espaços públicos, visto o descaso e abandono de grande parte desses locais. Em grande medida, o espaço público urbano é afetado juridicamente pelo regime de propriedade pública bem como ambientalmente pelas condições em que acontece a gestão patrimonial de responsabilidade das instâncias governamentais, segundo suas respectivas atribuições de preservação, regularização, controle, fiscalização, manutenção e sua utilização e destinação.

Diante do exposto, o objetivo do artigo é fazer uma reflexão sobre soluções que podem contribuir positivamente à qualidade de vida nas cidades, como as intervenções no meio urbano promovidas pela sociedade civil, visando o bem patrimonial público e espaços mais sustentáveis. Serão apresentados e discutidos alguns desses movimentos e suas principais ideias, que buscam mudar o cenário de abandono dos espaços urbanos. Além disso, serão apresentadas questões referentes aos principais aspectos da dimensão social da sustentabilidade e discutido se esta abordagem pode ser verificada nos casos apresentados. A metodologia aplicada foi de revisão bibliográfica sobre o tema e levantamento de casos, desde grandes projetos urbanos a pequenas soluções através de fontes secundárias e da bibliografia abordada.

\section{SUSTENTABILIDADE SOCIAL NO MEIO URBANO}

As discussões sobre o meio ambiente urbano no âmbito mundial surgiram de forma efetiva e organizada há mais de meio século. O desenvolvimento sustentável ou ecodesenvolvimento propõe como base o tripé: eficiência econômica, justiça social e prudência ecológica. Assim, temos como principais dimensões da sustentabilidade: sustentabilidade ecológica, que é a porta de entrada das discussões sobre sustentabilidade, onde são consideradas as diversas intervenções da sociedade na construção do espaço, onde se deve ser prudente quanto à utilização dos recursos naturais; sustentabilidade social, que se refere ao acesso a bens e serviços, na busca de viabilizar uma maior equidade de riquezas e oportunidades, buscando combater as práticas de exclusão, discriminação e reprodução da pobreza, e respeitar a diversidade e suas formas de expressão; e sustentabilidade econômica, que considera que a eficiência econômica deve ser medida em termos macrossociais e não através de critérios microeconômicos de rentabilidade empresarial.

Dempsey et al (2009) fazem uma revisão sobre a dimensão social do desenvolvimento sustentável, e afirmam que esse é um conceito multidimensional bastante abrangente, que aborda o questionamento de quais são os objetivos sociais da sustentabilidade, o que possibilita uma diversidade de respostas, sem um consenso de como suas metas podem ser definidas. Os autores descrevem alguns itens não-físicos envolvidos na dimensão social da sustentabilidade, dentre eles: educação e treinamento; justiça social; inclusão social; segurança; senso de pertencimento; organizações de bairro ativas; tradições culturais, e outros fatores físicos como: urbanidade; domínio público atrativo; boas residências; qualidade ambiental local; acessibilidade, desenho urbano sustentável; vizinhança; bairros transitáveis. Afirmam assim que o conceito de sustentabilidade social não é absoluto ou constante, mas que deve ser considerado algo dinâmico, que sofrerá variações conforme o tempo ou lugar, e de influências externas.

Para Gehl (2013), a sustentabilidade social permite "dar aos vários grupos da sociedade oportunidades iguais de acesso ao espaço público e também de se locomover pela cidade" e possui uma "importante dimensão democrática que prioriza acessos iguais para que encontremos 'outras pessoas' no espaço público". Para o autor, o espaço público deve ser acessível, convidativo e servir como cenário atraente para encontros organizados ou informais. A diversidade de atividades e atores nas cidades engendra oportunidades que reforçam a sustentabilidade social a partir do espaço público. 


\section{MOVIMENTOS AO LONGO DO MUNDO: BUSCANDO FAZER A DIFERENÇA}

São diversos os movimentos e respectivas denominações associados ao interesse das pessoas na participação da mudança das cidades, autonomamente a gestão pública, mas que vão ao encontro às necessidades reais dos habitantes das cidades e seus bairros. Muitas dessas ações são idealizadas e realizadas pelo denominado "Terceiro Setor", que é composto por agentes privados, cidadãos organizados visando fins públicos. Suas ações não geram lucro e buscam atender a necessidades coletivas. Eles atuam em grande medida, por caminhos menos burocratizados e não se submetem às decisões centralizadas de outros tipos de organizações, como as de cunho político.

Diamond (2014) apresenta três casos na cidade de Londres de pequenas intervenções para renovação do espaço público que utilizaram abordagens distintas para regeneração da cidade como um fenômeno sustentável. Dois deles são o Cadogan Café e Folly for a Flyver, que adotaram estratégias distintas para ativar o espaço público com os edifícios e a paisagem da cidade. A integração do Cadogan Café ocorreu devido ao mobiliário urbano, atrativo aos usuários, e o Folly for a Flyer é um edifício temporário sob um viaduto com espaços semi-privados que incluem áreas de comércio, café, cinema, eventos, vias exclusivas para pedestres e ciclistas.

Em Madri, em um terreno de $5500 \mathrm{~m}^{2}$ onde foi construído o Mercado de La Cebada no Século $\mathrm{XV}$, moradores vizinhos se organizaram para reativar as atividades esportivas, artísticas e recreativas do local em 2011, dando origem ao Campo de Cebada, composto por uma quadra de basquete e uma horta urbana, além de exibir muros grafitados que se renovam a cada seis meses. Todas as instalações foram construídas e são mantidas por meio de autogestão com participação dos moradores e grupos culturais (BARATTO, 2013).

Um caso icônico é o Highline Park, parque linear suspenso na cidade de Nova York, sob a antiga malha ferroviária. A área seria demolida pela prefeitura municipal, já que se encontrava abandonada e degradada, mas moradores do entorno fundaram o grupo Friends of the High Line, e apresentaram uma proposta para criação de um parque público no local, o que foi acatado e edificado, tornando-se um modelo de intervenção urbana e cartão postal da cidade.

No Brasil, foi lançado em 2010 o projeto "Cidades para pessoas", desenvolvido por uma jornalista especializada em planejamento urbano e uma artista plástica, Natália Garcia e Juliana Russo. Hoje, integram também o grupo Marcella Arruda e Raffaela Pastore. Inicialmente o projeto baseou-se nas ideias de Jan Gehl e em seus projetos. Em um segundo momento tais especialistas passaram a visitar projetos dado o interesse na melhoria da qualidade, apropriação e qualidade dos espaços públicos. Os principais focos da pesquisa eram: planejamento urbano e soluções clássicas, e novas ideias e paradigmas das cidades do futuro.

O movimento intitulado "I'm a City Changer," promovido pela ONU-Habitat, visa compartilhar e disseminar iniciativas individuais, públicas e corporativas que tenham como objetivo melhorar a cidade. A campanha foi lançada em 2012 na Conferência mundial da ONU - Rio +20, com o objetivo de criar cidades sustentáveis que se desenvolvam mediante seis fatores básicos: Cidade resiliente; Cidade verde; Cidade segura e saudável; Cidade inclusiva; Cidade planejada e Cidade produtiva.

Em 2011, foi conceituado o Tactical Urbanism, ou Urbanismo tático, que abrange atividades temporárias que destacam uma necessidade ou desejo da comunidade, também denominadas pelas expressões do-it yourself, pop-up urbanism e city repair. O termo Tactical Urbanism encobre uma enorme variedade de atividades e usos, como jardins e parques, ciclovias, compartilhamento de espaços por microempreendedores, vendedores de rua, entre outros (DAVIDSON, 2013). São projetos urbanos de baixo custo, fáceis de construir, com objetivo de atrair um tráfego de pedestres para a região, em especial nos centros das cidades. Se usado estrategicamente e com consciência, o TU pode ser uma ferramenta poderosa para destacar as necessidades de determinada área, mas exige um conhecimento consciente do poder e limitações deste tipo de estratégia. 
Já em 2013 foi lançado na Alemanha o livro Handmade Urbanism, ou urbanismo feito à mão, organizado por Marcos L. Rosa e Ute E. Weiland, que apresenta quinze iniciativas de intervenções "manuais" feitas pelos moradores de seus bairros, em cinco grandes cidades do mundo: Mumbai, São Paulo, Istambul, Mexico City e Cape Town. No handmade urbanism, os moradores reconhecem um problema e desenvolvem atividades visando solucionar a questão por meio de uma ideia central. As iniciativas comunitárias evolvem a partir dessas ações que dão suporte à participação ativa dos cidadãos na escala local. Suas ações são únicas, moldadas pelos indivíduos e pelas operações definidas pelos mesmos; são realizadas em escala local, como produtos de cultura e meio ambiente, envolvendo estrutura física e emocional, bem-estar, educação, visando a reformulação do ambiente construído. A maioria das ações é realizada pelos moradores, sem participação de governo ou profissionais.

Além desses movimentos globais e organizados, surgem atores da sociedade civil que se organizam em busca de melhorias no espaço público, ao assumir a manutenção de um playground ou "adotar" um canteiro central de certa avenida, criação de hortas comunitárias, dentre outros. Portanto o interesse de mudança buscando dotar os centros urbanos de uma adequada qualidade de vida é mundial, e a sociedade civil tem desempenhado um papel cada vez mais relevante em face de tais questões que são de responsabilidade dos gestores públicos.

Sumarizando, os movimentos citados compõem duas categorias de acordo com suas características: o Handmade Urbanism e Tactical Urbanism são conceitos para esses movimentos, mas não possuem envolvimento prático com a situação dos espaços públicos nas cidades, estabelecendo-se apenas como um campo teórico; os movimentos I'm a city changer e Cidades para pessoas incitam mudanças no comportamento das pessoas diante da realidade, além de apresentar questões importantes a se avaliar e considerar.

\section{CONSIDERAÇÕES FINAIS}

As preocupações com as questões de sustentabilidade e a melhoria da qualidade de vida nas cidades não podem ser ignoradas e estão presentes no mundo acadêmico, nos meios de comunicação e na vida das pessoas. Considerando que nas cidades os espaços públicos apresentam gradações quanto a sua utilização pela população, questiona-se quais as motivações e condições dos espaços serem amplamente utilizados pela população enquanto outros não, tornando-se até mesmo em locais abandonados, seja por falta de manutenção, sensação de insegurança, tipologias arquitetônicas que segregam a população ou uso do solo mais restritivo em determinada região. Tais locais públicos vazios, sem uso apontam à degradação e desconstrução da cidade, afastando as práticas de esporte, lazer, convivência.

No entanto, experiências verificadas em diversas partes do mundo parecem ser um indicativo da ineficiência da gestão patrimonial pelas instâncias governamentais, levando à postura de auto intervenção por parte da sociedade civil, visando o atendimento à função socioambiental do bem público. Os movimentos populares organizados pelas comunidades locais em todo mundo em busca de pequenas ou grandes mudanças nas cidades, por meio da autogestão ou mesmo com 0 apoio do poder público, atendem às demandas e necessidades locais.

\section{AGRADECIMENTOS}

O presente trabalho foi realizado com apoio da Coordenação de Aperfeiçoamento de Pessoal de Nível Superior - Brasil (CAPES) - Código de Financiamento 001

\section{REFERÊNCIAS}

BARATTO, R. Campo de Cebada em Madri: um projeto local de autogestão artística 02 Sep 2013. ArchDaily Brasil. Disponível em <http://www.archdaily.com.br/137915/campo-decebada-em-madri-um-projeto-local-de-autogestao-artistica>. Acesso em 08/01/2016. 
CIDADE PARA AS PESSOAS. Disponível em < http://cidadesparapessoas.com/> Acesso em 15/04/2019.

DAVIDSON, M. M. Tactical urbanism, public policy reform, + 'innovation spotting' by Government: form PARK (ing) day to San Francisco's parklets. Partial fulfillment of the requeriments for the degree of Master in City Planning at the Massachussetts Institute of Thecnology. June 2013.

DEMPESEY, N.; BRAMLEY, G.; POWER, S.; BROWN, C. The social dimensiono of sustainable development: defining urban social sustainability. In: Sustainable Development, 19, p.289-300, 2011.

DIAMOND, R. Changing building typologies fórum - Observation from practice. Allk the line: What do people really want from public space? In: The Journal of Space Syntax. V.5, n.2. p. 250-254, Dec. 2014.

GEHL, J. Cidades para pessoas. Tradução Anita Di Marco. 2.ed. São Paulo: Perspectiva, 2013.

HIGH LINE. Disponível em < https://www.thehighline.org/> Acesso em 10/02/2019.

UN HABITAT: For a better urban future. Disponível em < https://unhabitat.org/city-changertoolkit/> Acesso em 13/04/2019.

ROSA, M. L.; WEILAND, U. E. Handmade Urbanism: from community initiatives to participatory models. Berlin: Jovis Verlag GmbH, 2013. 